\title{
Combined proximal stent grafting plus distal bare metal stenting for management of aortic dissection: Superior to standard endovascular repair?
}

\author{
Sophie C. Hofferberth, BSc, BMedSc, ${ }^{a}$ Andrew E. Newcomb, MBBS, FRACS, ${ }^{\mathrm{b}}$ Michael Y. Yii, MBBS, \\ FRACS, ${ }^{\mathrm{b}}$ Kelvin K. Yap, MBBS, FRANZCR, ${ }^{\mathrm{c}}$ Raymond C. Boston, PhD, ${ }^{\mathrm{d}}$ Ian K. Nixon, MBBS, \\ FRACS, ${ }^{\text {b }}$ and Peter J. Mossop, MBBS, FRACR ${ }^{\mathrm{c}}$
}

\begin{abstract}
Objectives: The present study compared the outcomes between combined proximal descending aortic endografting plus distal bare metal stenting and conventional proximal descending aortic stent-graft repair in patients with type A and type B aortic dissection.
\end{abstract}

\begin{abstract}
Methods: From January 2003 to December 2010, 63 patients underwent endovascular treatment for acute (type A, 24; type B , 21) and chronic (type B, 18) aortic dissection. Of these, 40 patients underwent proximal descending aortic endografting plus distal bare metal stenting (group 1), and 23 underwent proximal descending stentgraft repair alone (group 2). All patients with type A dissection underwent open surgical intervention plus adjunctive retrograde endovascular repair.
\end{abstract}

\begin{abstract}
Results: The patients were comparable for baseline characteristics and treatment indicators, but more group 1 patients were active smokers $(P=.03)$. The intraoperative characteristics were also similar, although 4 patients, all in group 2 , developed malperfusion syndrome postoperatively $(P=.02)$. The overall hospital mortality was $6 \%$. At a mean follow-up of 49 months, 9 group 2 patients (43\%) required unplanned secondary intervention compared with 4 in group $1(11 \% ; P=.007)$. Reintervention for thoracoabdominal aortic aneurysm or visceral ischemia was performed in 4 patients $(19 \%)$ from group $2(P=.03)$. Late aortic-related deaths occurred in $1(5 \%)$ and $2(5 \%)$ patients in groups 1 and 2, respectively.
\end{abstract}

Conclusions: Combined proximal descending aortic endografting plus distal bare metal stenting for aortic dissection provides favorable short-term outcomes and decreases late distal aortic complications compared with conventional endovascular repair. These results support a more widespread application of this approach. A prospective, randomized trial is needed before definite conclusions can be made. (J Thorac Cardiovasc Surg 2012;144:956-62)

The past decade has seen the evolution of endovascular prostheses for the treatment of descending aortic dissection. Initial reports described the use of proximal stent-grafts to seal primary entry tears in type $\mathrm{B}$ dissection, ${ }^{1-3}$ and subsequent large series have reported encouraging early

From the Department of Medicine, ${ }^{\text {a }}$ St Vincent's Hospital, University of Melbourne, Fitzroy, Victoria, Australia; Department of Cardiac Surgery, ${ }^{\mathrm{b}}$ St Vincent's Hospital Melbourne, Melbourne, Victoria, Australia; Department of Medical Imaging, ${ }^{c}$ St Vincent's Hospital Melbourne, Melbourne, Victoria, Australia; and Department of Clinical Studies, ${ }^{\mathrm{d}}$ New Bolton Center, University of Pennsylvania School of Veterinary Medicine, Philadelphia, Pa.

Disclosures: Peter J. Mossop and Ian Nixon were involved in patenting the Zenith dissection stent; both receive a share of patent royalties from Cook, Inc, Bloomington, Ind. All other authors have nothing to disclose with regard to commercial support.

Read at the 92nd Annual Meeting of The American Association for Thoracic Surgery, San Francisco, California, April 28-May 2, 2012.

Received for publication March 27, 2012; revisions received May 23, 2012; accepted for publication July 9, 2012; available ahead of print Aug 13, 2012.

Address for reprints: Sophie C. Hofferberth, BSc, BMedSc, Department of Medicine, St. Vincent's Hospital, Melbourne, Level 4, Clinical Sciences Building, Fitzroy, Victoria 3065, Australia (E-mail: s.hofferberth@ugrad.unimelb.edu.au).

$0022-5223 / \$ 36.00$

Copyright (C) 2012 by The American Association for Thoracic Surgery

http://dx.doi.org/10.1016/j.jtcvs.2012.07.007 results. ${ }^{4-6}$ The use of stent grafts in type A dissection has been described in conjunction with open surgical techniques to address distal aortic complications. ${ }^{7-9}$ Stentgrafting the distal dissected aorta aims to decompress the thoracic false lumen, with resultant thrombosis and remodeling.

However, even after successful thoracic stent-graft placement, the fate of the distal thoracoabdominal aortic segment often remains unresolved. Proximal endograft closure can result in incomplete aortic repair, with the abdominal aorta failing to remodel in $50 \%$ to $80 \%$ of cases. ${ }^{4}$ This risks complications such as malperfusion, aneurysmal degeneration, and rupture. To achieve more complete aortic reconstruction, our group developed the novel endovascular treatment strategy of combined descending aortic endografting plus distal bare metal stenting to manage aortic dissection, a technique we termed "Staged Total Aortic and Branch vesseL Endovascular reconstruction" (STABLE). ${ }^{10-12}$ The purpose of the present study was to compare the outcomes of standard proximal descending aortic stentgrafting to the more radical STABLE approach in treating type A and type B aortic dissection. 


\section{Abbreviations and Acronyms}

CTA = computed tomography angiography

STABLE $=$ staged total aortic and branch vessel endovascular reconstruction

\section{MATERIALS AND METHODS}

A retrospective review of the cardiovascular surgical database at St Vincent's Hospital, Melbourne, was performed from January 2003 to December 2010. The patients' medical records were reviewed for the preoperative patient characteristics, dissection morphology, details of the operative strategy, intraoperative events, and postoperative course.

From January 2003 to December 2010, 117 patients presented to our tertiary referral center with type A or type B aortic dissection. Of these 117 patients, 63 underwent endovascular treatment for repair of acute (type $\mathrm{A}$ in 24 and type $\mathrm{B}$ in 21) and chronic (type B in 18) aortic dissection. These 63 patients were separated into group $1(n=40$; acute type $A$ in 14 , chronic type $A$ in 2, acute type $B$ in 16 , and chronic type $B$ in 8 ), who underwent STABLE repair, and group $2(\mathrm{n}=23$; acute type $\mathrm{A}$ in 6 , chronic type $\mathrm{A}$ in 2 , acute type $B$ in 10 , and chronic type $B$ in 5), who underwent proximal stent-graft therapy alone as the control group. The type of endovascular repair undertaken was determined by the treating surgeon.

The St Vincent's Hospital ethics committee approved this retrospective study and waived the need for individual patient consent. All patients gave informed consent for each procedure.

\section{Data Collection and Analysis}

The data were analyzed using SPSS software, version 20.0 (SPSS Inc, Chicago, Ill). Student's $t$ test was used to assess the differences in numeric variables. Fisher's exact test was used to assess the differences in categorical values.

\section{Endovascular Prosthesis and Procedure}

Baseline computed tomography angiography (CTA) with multiplanar reconstruction was performed to assess the feasibility of the endovascular procedure, patency of the visceral vessels, choice of peripheral access site, and sizing of the stent grafts. All patients were treated under general anesthesia.

A detailed description of the Zenith Dissection Endovascular System (Cook, Inc, Bloomington, Ind) has been previously reported. ${ }^{10-12}$ The STABLE procedure involved endograft closure of the proximal entry tear and distal bare metal Z-stenting. Patients with type A dissection underwent open surgical intervention, as indicated, plus adjunctive retrograde proximal endograft deployment with bare metal stenting in cases in which dissection extended beyond the resected aorta. The extent of bare metal stenting was determined by the distal extension of the dissection and any branch vessel or true lumen compromise.

The common femoral artery was used for peripheral access in all patients. Fluoroscopy and transesophageal echocardiography were used to guide placement of a guidewire over a pigtail catheter maneuvered in the true lumen. The Zenith TX2 graft was then advanced and deployed. Aortography and transesophageal echocardiography were subsequently performed to ensure accurate stent-graft placement, and, in cases of type B dissection, to assess appropriate exclusion of the proximal entry tear. The delivery systems were exchanged and the Zenith dissection endovascular stent was then advanced and deployed, overlapping 1 stent body with the proximal stent-graft. Among the group 2 patients, 21 (91\%) underwent treatment with the Cook Zenith TX2 thoracic TAA endovascular graft (Cook Medical Inc), 1 patient received a Luminexx vascular stent (R Bard Inc, Murray Hill, NJ), and 1 patient received a Fluency plus vascular stent graft (Bard, Inc, Tempe, Ariz).
Distal adjunctive procedures were undertaken if secondary entry tears were identified. The endovascular techniques used included aortic endografting, covered stent insertion in branch vessels, or embolization using coils or glue.

\section{Follow-up Imaging}

Serial CTA was performed to measure true lumen expansion, aortic growth, and false lumen perfusion at the latest follow-up CTA.

\section{RESULTS \\ Preoperative and Procedural Characteristics}

The preoperative risk factors were similar in groups 1 and 2 (Table 1). However, more group 1 patients were active smokers (12 vs $1, P=.02$ ). The intraoperative characteristics among the patients with type A dissection were comparable between the 2 groups (Table 1). Predictably, a greater mean number of devices were deployed in the group 1 patients than in the group 2 patients ( 3.1 vs $1.8, P=.001$ ). In group 1 , distal bare metal stent coverage extended to the infrarenal aorta in $9(56 \%)$ and $16(67 \%)$ patients with type A and type B dissection, respectively.

\section{In-Hospital Outcomes}

The postoperative complications did not differ between the 2 groups (Table 2). The in-hospital incidence of bowel ischemia or malperfusion was significantly greater in group 2 (n $=4, P=.01$; Table 2$)$. Of these 4 patients, $2(9 \%)$ with acute type $\mathrm{B}$ dissection developed mesenteric ischemia, 1 of whom also developed limb and spinal cord ischemia and required a prolonged hospital stay. The other patient developed hypotension and acidosis soon after leaving the operating room and died 24 hours later. The remaining 2 patients required reintervention to treat their bowel malperfusion. One with chronic type B dissection had a prolonged hospital stay complicated by superior mesenteric artery and renal artery malperfusion, necessitating additional stent-graft insertion. Surgical reintervention (right external iliac artery to superior mesenteric artery bypass) was required in the other patient with acute type B dissection 8 days after the primary procedure. The hospital mortality was $5 \%$ ( 2 of 40 patients; acute type $\mathrm{A}$ in 1 and acute type B in 1) in group 1 and $9 \%$ (2 of 23 patients; acute type $\mathrm{B}$ in 2) in group 2 (Table 2). One intraoperative death occurred in each group.

\section{Follow-up Outcomes}

The mean follow-up was 49 months (range, 5-115). The overall actuarial survival was $80 \%$ in group 1 and $70 \%$ in group 2, with 6 late deaths in group 1 and 4 in group $2(P=.73$; Table 3$)$. In group 1,1 death $(3 \%)$ was aortic related, and 5 patients died of unrelated conditions, including myocardial infarction in 2 , disseminated carcinoma in 2 , and complications secondary to a fractured femur in 1 . Another patient died 24 hours after pacemaker insertion 
TABLE 1. Baseline characteristics and preoperative clinical status

\begin{tabular}{lccc}
\hline \multicolumn{1}{c}{ Variable } & $\begin{array}{c}\text { STABLE group } \\
(\mathbf{n}=\mathbf{4 0})\end{array}$ & $\begin{array}{c}\text { Control } \\
(\mathbf{n}=\mathbf{2 3})\end{array}$ & $\begin{array}{c}\boldsymbol{P} \\
\text { value }\end{array}$ \\
\hline Age (y) & $55 \pm 13$ & $61 \pm 12$ & .10 \\
Male gender & $29(73)$ & $14(61)$ & .40 \\
Marfan syndrome & $2(5)$ & 0 & .53 \\
Hypertension & $30(75)$ & $21(91)$ & .18 \\
Hypercholesterolemia & $12(30)$ & $7(30)$ & 1 \\
Diabetes mellitus & $3(8)$ & $4(17)$ & .25 \\
Active smoking & $12(30)$ & $1(4)$ & .02 \\
Previous CVA & $2(5)$ & $1(4)$ & 1 \\
History of aortic dissection & $5(13)$ & $4(17)$ & .71 \\
History of AAA & $1(3)$ & 0 & 1 \\
Previous cardiovascular surgery & $9(23)$ & $5(22)$ & 1 \\
AVR & $1(3)$ & $1(4)$ & 1 \\
MVR & $2(5)$ & 0 & .53 \\
CABG & $2(5)$ & $1(4)$ & 1 \\
$\quad$ Type A aortic dissection repair & $4(10)$ & $3(13)$ & .69 \\
Malperfusion & $25(63)$ & $13(57)$ & .78 \\
Cardiac & $2(5)$ & $1(4)$ & 1 \\
Cerebral & $3(8)$ & $2(9)$ & 1 \\
Visceral(celiac, mesenteric, renal) & $16(40)$ & $9(39)$ & 1 \\
Iliofemoral & $7(18)$ & $5(22)$ & .75 \\
Both (visceral and iliofemoral) & $2(5)$ & 0 & .53 \\
\hline Daprat
\end{tabular}

Data presented as mean $\pm \mathrm{SD}$ or $\mathrm{n}(\%) . A A A$, Abdominal aortic aneurysm; $A V R$, aortic valve replacement; $C A B G$, coronary artery bypass grafting; $C V A$, cerebrovascular accident; $M V R$, mitral valve replacement; STABLE, staged total aortic and branch vessel endovascular reconstruction.

for complete heart block. At autopsy, the aorta was intact. The aortic-related death occurred in a 71-year-old woman with chronic aneurysmal type B dissection causing visceral malperfusion. After undergoing STABLE repair, a re-entry tear remained in the left renal artery, because stent deployment was not deemed technically possible. She underwent emergency reintervention 4 weeks later for acute aneurysmal expansion of the thoracic aorta. False lumen perfusion persisted, and she died suddenly 4 months later of aortic rupture. Among the group 2 patients, late mortality occurred secondary to pancreatic cancer in 1 and respiratory failure in another. The other 2 late deaths $(9 \%)$ were aortic related. One died of abdominal aortic aneurysm rupture 11 months after repair of acute type B dissection. Another died of multiorgan failure secondary to a ruptured $9.5-\mathrm{cm}$ abdominal aortic aneurysm 6 years after primary repair of acute type B dissection.

The requirement for an unplanned secondary reintervention differed significantly between the 2 cohorts, with 4 of 38 in group 1 versus 9 of 21 in group $2(P=.007$; Table 3 ). In group 1,3 patients ( $8 \%$; acute type $A$ in 1 , acute type $B$ in 1 , and chronic type $B$ in 1) required secondary endovascular reintervention (Table 3). Additional stent-graft deployment was undertaken to treat proximal stent migration leading to left subclavian artery dissection in 1, type 1 endoleak in 1 , and a retroperitoneal hematoma in 1 patient. Finally, 1 patient in group $1(3 \%$, acute type B)
TABLE 2. Intraprocedural details and postoperative outcomes

\begin{tabular}{|c|c|c|c|}
\hline Variable & $\begin{array}{l}\text { STABLE group } \\
\quad(\mathbf{n}=\mathbf{4 0})\end{array}$ & $\begin{array}{l}\text { Control group } \\
\quad(\mathbf{n}=\mathbf{2 3})\end{array}$ & $\begin{array}{c}P \\
\text { value }\end{array}$ \\
\hline \multicolumn{4}{|l|}{ Procedural characteristics } \\
\hline \multicolumn{4}{|l|}{$\begin{array}{l}\text { Average interval to } \\
\text { intervention (d) }\end{array}$} \\
\hline Acute & $5.4 \pm 4.2$ & $4.9 \pm 5.2$ & .72 \\
\hline Chronic & & & .13 \\
\hline Median & 48 & 56 & \\
\hline Range & $20-1095$ & $15-388$ & \\
\hline Devices deployed (n) & $3.1 \pm 1.7$ & $1.8 \pm 1.3$ & .001 \\
\hline $\begin{array}{l}\text { Coverage of left subclavian } \\
\text { artery }\end{array}$ & $5(13)$ & $6(26)$ & .30 \\
\hline $\begin{array}{l}\text { Supra-aortic branch vessel } \\
\text { involvement (type A) }\end{array}$ & $6(15)$ & $5(22)$ & .51 \\
\hline \multicolumn{4}{|l|}{$\begin{array}{l}\text { Adjunctive procedures at } \\
\text { primary intervention }\end{array}$} \\
\hline Distal stent graft extension & $7(18)$ & $3(13)$ & .73 \\
\hline \multicolumn{4}{|l|}{$\begin{array}{l}\text { Branch vessel covered } \\
\text { stent graft }\end{array}$} \\
\hline Renal artery & $5(13)$ & $1(4)$ & .40 \\
\hline Mesenteric artery & 0 & $1(4)$ & .36 \\
\hline Iliofemoral vasculature & $1(3)$ & $3(13)$ & .13 \\
\hline Embolization (coils, glue) & $9(23)$ & $4(17)$ & .75 \\
\hline Carotid-subclavian bypass & 0 & $2(9)$ & .12 \\
\hline Access vessel repair & $1(3)$ & $2(9)$ & .55 \\
\hline \multicolumn{4}{|l|}{ Intraprocedural results } \\
\hline Deaths & 0 & $1(4)$ & .36 \\
\hline Complications & $1(3)$ & $2(9)$ & .55 \\
\hline \multicolumn{4}{|l|}{ In-hospital morbidity } \\
\hline Stroke & $2(5)$ & $1(4)$ & 1 \\
\hline $\begin{array}{l}\text { Bowel } \\
\text { ischemia/malperfusion }\end{array}$ & 0 & $4(17)$ & .01 \\
\hline $\begin{array}{l}\text { Requiring surgical } \\
\text { intervention }\end{array}$ & 0 & $1(4)$ & .36 \\
\hline $\begin{array}{l}\text { Transient spinal cord } \\
\text { ischemia }\end{array}$ & 0 & $1(4)$ & .36 \\
\hline Limb ischemia & 0 & $2(9)$ & .12 \\
\hline Acute renal failure & $6(15)$ & $5(22)$ & .51 \\
\hline Permanent dialysis & 0 & 0 & 0 \\
\hline Myocardial infarction & $2(5)$ & 0 & .53 \\
\hline ICU stay (d) & $3.6 \pm 6.8$ & $3.7 \pm 8.8$ & .88 \\
\hline Hospital stay (d) & $13.6 \pm 10.8$ & $13.7 \pm 15.6$ & .58 \\
\hline \multicolumn{4}{|l|}{ Mortality } \\
\hline 30-d/In-hospital & $2(5)$ & $2(9)$ & .62 \\
\hline
\end{tabular}

Data presented as mean $\pm \mathrm{SD}$ or $\mathrm{n}(\%)$. ICU, Intensive care unit; STABLE, staged total aortic and branch vessel endovascular reconstruction.

required open reoperation after developing proximal endograft infection, leading to aortobronchial fistula formation (Table 3).

Among the group 2 patients, 7 (33\%; acute type A in 1, acute type $\mathrm{B}$ in 5 , and chronic type $\mathrm{B}$ in 1) underwent unplanned secondary endovascular reintervention, and 2 $(10 \%$; acute type $\mathrm{A}$ in 1 and acute type $\mathrm{B}$ in 1$)$ required surgical reintervention (Table 3 ). One patient required covered stent graft deployment and coil embolization of the right 
TABLE 3. Long-term survival and secondary cardiovascular interventions

\begin{tabular}{lccc}
\hline \multicolumn{1}{c}{ Variable } & $\begin{array}{c}\text { STABLE group } \\
(\mathbf{n}=\mathbf{3 8})\end{array}$ & $\begin{array}{c}\text { Control group } \\
(\mathbf{n}=\mathbf{2 1})\end{array}$ & $\begin{array}{c}\boldsymbol{P} \\
\text { Value }\end{array}$ \\
\hline Secondary interventions & $4(11)$ & $9(43)$ & .007 \\
$\quad$ Surgical & $1(3)$ & $2(10)$ & .28 \\
$\quad$ Endovascular & $3(8)$ & $7(33)$ & .03 \\
Late distal aortic & 0 & $4(19)$ & .01 \\
$\quad$ reintervention & & & \\
Aneurysmal degeneration & 0 & $3(14)$ & .04 \\
$\quad$ Visceral ischemia & 0 & $1(5)$ & .35 \\
Late adverse events & & & \\
$\quad$ Stroke & $1(3)$ & $2(10)$ & .28 \\
$\quad$ Permanent dialysis & 0 & $1(5)$ & .36 \\
Late mortality & $6(16)$ & $4(19)$ & .73 \\
\hline
\end{tabular}

Data presented as n (\%). STABLE, Staged total aortic and branch vessel endovascular reconstruction.

common carotid artery to treat a proximal re-entry tear causing arch growth. The patient recovered uneventfully, with no evidence of residual dissection. Two patients underwent extension of the Cook-TX2 stent-graft for type 1 endoleak, with one receiving concurrent left subclavian artery coil embolization. Four $(19 \%$; three with acute and one with chronic type B dissection) required distal aortic reintervention. One patient received additional branch graft covered stent-grafting for renal malperfusion, and three $(14 \%)$ underwent endograft repair of thoracoabdominal aortic aneurysms. Of these patients, 1 died of a continuously expanding abdominal aortic aneurysm 13 months after secondary intervention (Table 2) and 1 experienced dislocation of the extension stent-graft, necessitating additional open surgical reintervention. The other surgical reintervention was an aortic root replacement because of severe aortic regurgitation caused by noncoronary cusp necrosis.

\section{Aortic Remodeling}

Of the 38 survivors in group 1, at least 1 follow-up CTA ( $>6$ months) was available for 32 patients $(84 \%$; Table 4 and Figure 1). Of the 21 group 2 hospital survivors, $13(62 \%)$ had follow-up CTA scans available (Table 4). In group 1, the maximal aortic diameters remained stable

TABLE 4. Status of false lumen

\begin{tabular}{lccc}
\hline & $\begin{array}{c}\text { Complete } \\
\text { false lumen } \\
\text { thrombosis }\end{array}$ & $\begin{array}{c}\text { Partial } \\
\text { false lumen } \\
\text { thrombosis }\end{array}$ & $\begin{array}{c}\text { Fully patent } \\
\text { false lumen }\end{array}$ \\
\hline $\begin{array}{l}\text { Group 1 }(\mathrm{n}=32) \\
\text { Thoracic }\end{array}$ & $23(72)$ & $4(12)$ & $5(16)$ \\
Abdominal & $13(40)$ & $6(20)$ & $13(40)$ \\
Group 2 $(\mathrm{n}=13)$ & & & \\
Thoracic & $6(46)$ & $6(46)$ & $1(8)$ \\
Abdominal & $2(15)$ & $3(23)$ & $8(62)$ \\
\hline
\end{tabular}

Data presented as $\mathrm{n}(\%)$. from baseline to the latest radiologic follow-up examination (thoracic aorta $42.3 \pm 13.3 \mathrm{~mm}, P=.89$; abdominal aorta $30.4 \pm 6.8 \mathrm{~mm}, P=.88$ ). The true lumen index (true lumen diameter/total aortic diameter) increased significantly in both the thoracic $(0.42 \pm 0.2$ to $0.74 \pm 0.2$, $P=<.001$ and abdominal aorta $(0.48 \pm 0.2$ to $0.70 \pm$ $0.2, P=<.001)$ from baseline to the latest follow-up examination. In group 2, the maximal aortic diameter increased by more than $5 \mathrm{~mm}(41.1 \pm 11$ to $48.9 \pm 8 \mathrm{~mm}$, $P=.06)$ in the thoracic aorta, and the abdominal aorta displayed significant growth at the latest follow-up examination $(26.9 \pm 6.3$ to $35.6 \pm 15 \mathrm{~mm}, P=.05)$. The true lumen index increased significantly in the thoracic aorta ( $0.48 \pm 0.1$ to $0.65 \pm 0.2, P=.03$ ); however, no significant expansion occurred in the abdominal aorta $(0.54 \pm 0.3$ to $0.63 \pm 0.30, P=.52$ ) from baseline to the latest followup examination. The false lumen status at the latest follow-up examination is listed in Table 4.

\section{DISCUSSION}

The rationale for endovascular treatment of aortic dissection has been based on exclusion of the false lumen from the circulation. Exclusion of the proximal entry tear aims to decompress the thoracic false lumen, with resultant thrombosis and induction of aortic remodeling. However, with this limited approach, the distal thoracoabdominal aspect of the dissected aorta fails to remodel in $50 \%$ to $80 \%$ of cases. ${ }^{4}$ This is likely because of the presence of multiple re-entry tears leading to distal communication sites between the true and false lumens. Furthermore, the flapping motion of the dissecting lamella prevents induction of complete false lumen thrombosis in the distal thoracoabdominal aorta. Incomplete aortic repair using the limited proximal endograft approach leaves the patient at risk of late complications, including aneurysmal degeneration, extension of dissection, distal reoperation, or rupture. Adjunctive stentgraft deployment to cover distal thoracic re-entry tears above the celiac trunk might enhance false lumen thrombosis. However, coverage greater than $20 \mathrm{~cm}$ leads to an increased risk of spinal cord ischemia. ${ }^{13}$ Moreover, this approach does not adequately address distal true lumen collapse and the consequent risk of visceral branch malperfusion.

To address the late distal aortic complications associated with incomplete true lumen reconstitution, aneurysmal degeneration, and ongoing false lumen patency, our group developed the STABLE technique, a novel approach using combined descending aortic proximal endografting with distal bare metal stenting. ${ }^{11,12}$ Subsequently, a number of small case series have reported the use of bare metal stents in the distal thoracoabdominal aorta. ${ }^{14-16}$ Nienaber and colleagues ${ }^{16}$ used adjunctive or staged implantation of bare metal stents in 12 patients with complicated type $\mathrm{B}$ dissection, reporting favorable short-term results. In 


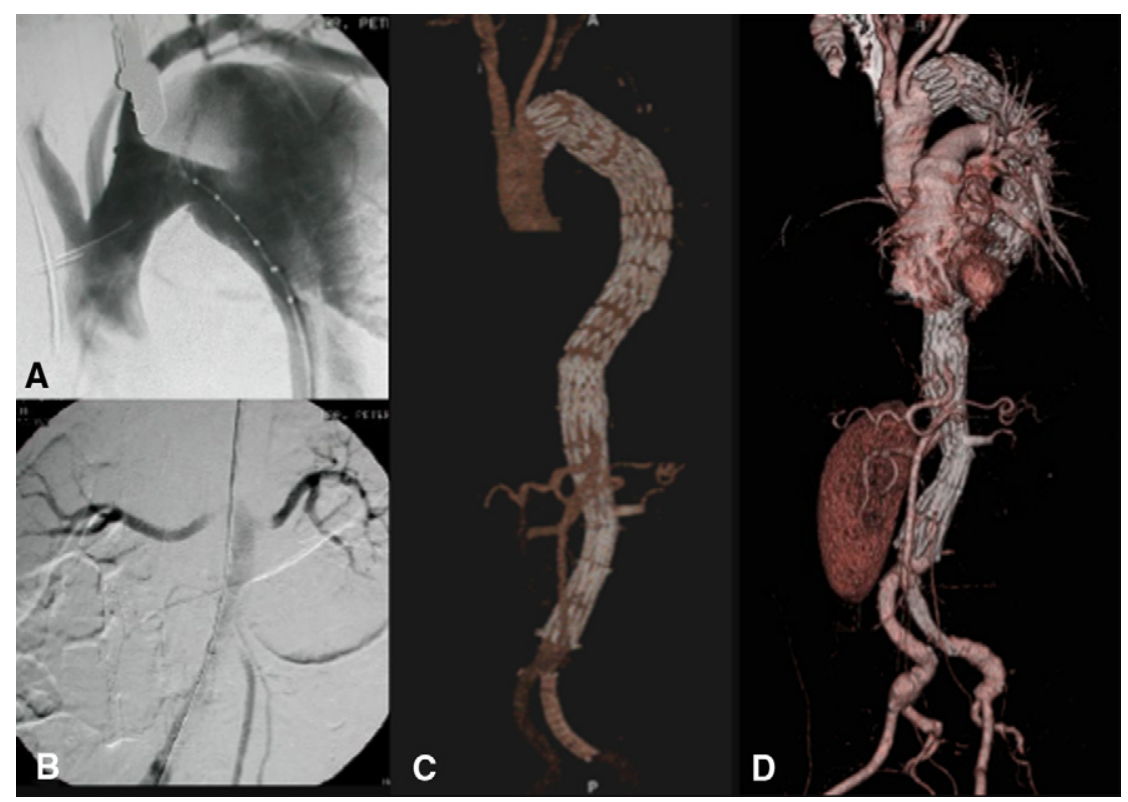

FIGURE 1. Preoperative digital subtraction angiogram of acute type B dissection demonstrating, (A) extensive primary entry tear with proximal aneurysm, with, (B) true lumen collapse and visceral malperfusion. C, Postoperative 3-dimensional computed tomography angiogram after successful deployment of thoracic TX2 endograft and bare metal stents in the abdominal aorta and left renal and iliac arteries. D, Three-dimensional computed tomography angiogram at 8 years of follow-up demonstrating aortic stability with complete false lumen thrombosis of the thoracoabdominal aorta.

2008, Melissano and colleagues ${ }^{15}$ reported early outcomes using the same Zenith dissection stent that was used in our cohort in 11 selected patients with chronic type B dissection. A clinical success rate of $91 \%$ was reported at 12 months, with $0 \%$ mortality, stroke, or paraplegia. We recently published the midterm results of our initial case series using the STABLE technique for type A and type B aortic dissection. ${ }^{10}$ The study demonstrated low periprocedural morbidity and mortality, with favorable distal aortic remodeling at 57 months. Initial reports from the singlearm, multicenter STABLE trial (investigating the use of proximal TX2 thoracic stent grafts and distal bare metal dissection stents) in complicated type B dissection have demonstrated favorable clinical and anatomic outcomes at 1 year of follow-up. ${ }^{17}$

To our knowledge, the present study is the first to compare the outcomes between standard endovascular repair and STABLE repair. Our contemporary comparison with the established proximal descending aortic stent-graft repair technique has confirmed the significantly improved patient outcomes in the acute and remote phases of the dissection pathology. The rationale for deployment of the dissection-specific bare Z-stent is to provide rapid support and immediate expansion of the aortic true lumen. This reverses distal true lumen collapse and enhances distal branch vessel flow, thereby acting against malperfusion. $^{11,14}$ The results of the present study have demonstrated that the addition of bare metal scaffolding in the distal thoracoabdominal aorta significantly reduces visceral malperfusion in the acute phase compared with standard endovascular repair ( $\mathrm{n}=0$ vs $\mathrm{n}=4 ; P=.02$ ). Moreover, this was achieved without increasing periprocedural morbidity or mortality.

\section{Aortic Remodeling}

Aortic growth has been identified as a major predictor of poor long-term prognosis in aortic dissection. ${ }^{18,19}$ It invites the risk of aneurysmal degeneration and the subsequent need for distal reintervention. Studies have shown that proximal stent grafting reduces aneurysmal degeneration and enhances the true lumen index in the thoracic aorta ${ }^{20}$; however, late expansion of the thoracoabdominal aorta has been reported. ${ }^{21}$ The STABLE repair addresses this deficiency by preventing growth of the abdominal aorta and significantly increasing the true lumen index at midterm follow-up compared with standard endovascular repair. The differences in aortic remodeling have been reflected in the significantly different late clinical outcomes seen in the 2 cohorts. The standard endovascular repair cohort displayed significantly greater rates $(19 \%$ vs $0 \%, P=.01)$ of late distal aortic reintervention for aneurysm formation or visceral ischemia. This also accounted for the significantly greater overall reintervention rate among those who received proximal stent-graft repair only.

The achievement of false lumen thrombosis has been established as a primary therapeutic goal, ${ }^{5,21-23}$ with ongoing false lumen perfusion shown to predict late mortality. ${ }^{22}$ The limited CTA follow-up prevented a robust method of 
comparison; however, the STABLE cohort appeared to achieve greater rates of complete thrombosis. Nevertheless, it is noteworthy that most STABLE patients still exhibited persistent false lumen perfusion, and this group included all 4 patients who required late reintervention and the single patient who died of aortic-related causes. The present study has shown that both treatment approaches fail to achieve complete false lumen thrombosis in the abdominal aorta in most cases. However, in the case of the STABLE repair, the residual false lumen perfusion has not been associated with an increasing aortic diameter or a worsening true lumen index. We tended to manage residual false lumen perfusion conservatively in stable patients. Our impression has been that a balance can be achieved by careful radiologic follow-up assessing for changing aortic dimensions to predict impending complications. This allows tolerance of residual false lumen perfusion in patients with stable aortic dimensions, permitting timely intervention, where necessary.

\section{Study Limitations}

Our study had several limitations. It was a retrospective, nonrandomized, single-institution study. The study populations were heterogeneous in dissection type, and certain aspects of therapy were customized to each patient. It solely reflects our own efforts to improve the unsatisfactory long-term results with standard endovascular repair in the management of aortic dissection. The incomplete CTA follow-up, particularly among the standard endovascular repair group, was a weakness of our study. We also acknowledge that the more radical STABLE approach exposes those with uncomplicated dissection to potential proceduralrelated risks and greater treatment costs. However, by reducing the late aortic complications seen in these patients, we have aimed to offset the ongoing cost of treating these complications. Nonetheless, we believe this is the first study to compare the results of standard proximal-stent graft repair with the relatively novel STABLE approach. The complete clinical data and significant length of follow-up have enabled a robust comparison of the 2 techniques, thereby adding valuable information to previous case series. The present study has provided a proof of concept for the use of the STABLE procedure in aortic dissection.

\section{CONCLUSIONS}

Combined descending aortic endografting with distal bare metal stenting prevents malperfusion in the acute phase and decreases late distal aortic complications compared with conventional endovascular repair in type A and type B aortic dissection. The STABLE technique represents a work in progress. With additional refinement of this technique, the results are likely to improve further and become more universally applicable in the management of aortic dissection. A multicenter, prospective, randomized trial is warranted to find a definitive answer regarding this treatment strategy.

\section{References}

1. Dake MD, Kato N, Mitchell RS, Semba CP, Razavi MK, Shimono T, et al. Endovascular stent-graft placement for the treatment of acute aortic dissection. N Engl J Med. 1999;340:1546-52.

2. Nienaber CA, Fattori R, Lund G, Dieckmann C, Wolf W, von Kodolitsch Y, et al. Nonsurgical reconstruction of thoracic aortic dissection by stent-graft placement N Engl J Med. 1999;340:1539-45.

3. Cambria RP, Brewster DC, Lauterbach SR, Kaufman JL, Geller S, Fan CM, et al. Evolving experience with thoracic aortic stent graft repair. J Vasc Surg. 2002;35: 1129-36.

4. Eggebrecht H, Nienaber CA, Neuhauser M, Baumgart D, Kische S, Schmermund A, et al. Endovascular stent-graft placement in aortic dissection: a meta-analysis. Eur Heart J. 2006;27:489-98.

5. Rodriguez JA, Olsen DM, Lucas L, Wheatley G, Ramaiah V, Diethrich EB. Aortic remodeling after endografting of thoracoabdominal aortic dissection. $J$ Vasc Surg. 2008;47:1188-94.

6. Tsai TT, Evangelista A, Nienaber CA, Trimarchi S, Sechtem U, Fattori R, et al. Long-term survival in patients presenting with type A acute aortic dissection: insights from the International Registry of Acute Aortic Dissection (IRAD). Circulation. 2006;114(1 Suppl):I350-6.

7. Jakob H, Tsagakis K, Tossios P, Massoudy P, Thielmann M, Buck T, et al. Combining classic surgery with descending stent grafting for acute DeBakey type I dissection. Ann Thorac Surg. 2008;86:95-101.

8. Pochettino A, Brinkman WT, Moeller P, Szeto WY, Moser W, Cornelius K, et al. Antegrade thoracic stent grafting during repair of acute DeBakey I dissection prevents development of thoracoabdominal aortic aneurysms. Ann Thorac Surg. 2009;88:482-90.

9. Uchida N, Ishihara H, Shibamura H, Kyo Y, Ozawa M. Midterm results of extensive primary repair of the thoracic aorta by means of total arch replacement with open stent graft placement for an acute type A aortic dissection. J Thorac Cardiovasc Surg. 2006;131:862-7.

10. Hofferberth SC, Foley PT, Newcomb AE, Yap KK, Yii MY, Nixon IK, et al. Combined proximal endografting with distal bare-metal stenting for management of aortic dissection. Ann Thorac Surg. 2012;93:95-102.

11. Mossop P, Nixon I, Oakes J, Devine TJ, McLachlan CS. Immediate "total" aortic true lumen expansion in type A and B acute aortic dissection after endovascular aortic endografting and GZSD bare stenting. J Thorac Cardiovasc Surg. 2007; 134:1360-2

12. Mossop PJ, McLachlan CS, Amukotuwa SA, Nixon IK. Staged endovascular treatment for complicated type B aortic dissection. Nat Clin Pract Cardiovasc Med. 2005;2:316-21; quiz 22

13. Buth J, Harris PL, Hobo R, van Eps R, Cuypers P, Duijm L, et al. Neurologic complications associated with endovascular repair of thoracic aortic pathology: incidence and risk factors. a study from the European Collaborators on Stent/ Graft Techniques for Aortic Aneurysm Repair (EUROSTAR) registry. J Vasc Surg. 2007;46:1103-11.

14. Ito N, Tsunoda T, Nakamura M, Iijima R, Matsuda K, Suzuki T, et al. Percutaneous bare Z-stent implantation as an alternative to surgery for acute aortic dissection with visceral ischemia. Catheter Cardiovasc Interv. 2003;58: 95-100.

15. Melissano G, Bertoglio L, Kahlberg A, Baccellieri D, Marrocco-Trischitta MM Calliari F, et al. Evaluation of a new disease-specific endovascular device for type B aortic dissection. J Thorac Cardiovasc Surg. 2008;136:1012-8.

16. Nienaber CA, Kische S, Zeller T, Rehders TC, Schneider H, Lorenzen B, et al. Provisional extension to induce complete attachment after stent-graft placement in type B aortic dissection: the PETTICOAT concept. J Endovasc Ther. 2006;13: 738-46.

17. Lombardi JV, Cambria RP, Nienaber CA, Chiesa R, Teebken O, Lee A, et al. Prospective multicenter clinical trial (STABLE) on the endovascular treatment of complicated type B aortic dissection using a composite device design. $J$ Vasc Surg. 2012;55:629-40.

18. Davies RR, Gallo A, Coady MA, Tellides G, Botta DM, Burke B, et al. Nove measurement of relative aortic size predicts rupture of thoracic aortic aneurysms. Ann Thorac Surg. 2006;81:169.

19. Elefteriades JA, Lovoulos CJ, Coady MA, Tellides G, Kopf GS, Rizzo JA. Management of descending aortic dissection. Ann Thorac Surg. 1999;67:2002-5, 14-9. 
20. Nathanson DR, Rodriguez-Lopez JA, Ramaiah VG, Williams J, Olsen DM, Wheatley GH, et al. Endoluminal stent-graft stabilization for thoracic aortic dissection. J Endovasc Ther. 2005;12:354.

21. Schoder M, Czerny M, Cejna M, Rand T, Stadler A, Sodeck GH, et al. Endovascular repair of acute type B aortic dissection: long-term follow-up of true and false lumen diameter changes. Ann Thorac Surg. 2007;83:1059-66.

22. Bernard Y, Zimmermann H, Chocron S, Litzler JF, Kastler B, Etievent JP, et al. False lumen patency as a predictor of late outcome in aortic dissection. Am J Cardiol. 2001;87:1378-82.

23. Halstead JC, Meier M, Etz C, Spielvogel D, Bodian C, Wurm M, et al. The fate of the distal aorta after repair of acute type A aortic dissection. J Thorac Cardiovasc Surg. 2007;133:127-35.

\section{Discussion}

Dr Charles R. Bridges (Charlotte, NC). I enjoyed your presentation very much. Could you enlighten us slightly about the mechanism of the results you observed? Correct me if I am wrong, but you saw increased overall aortic growth in the proximal group compared with the STABLE group, but you found enlargement of the true lumen in the STABLE group compared with the proximal group. Can you help us to understand the mechanics of how the bare metal stent affects remodeling?

For example, one might propose that the decreased incidence of malperfusion syndromes relates to the stabilizing aspect of that bare metal stent in the STABLE group; however, in terms of the change in the relative aortic dimensions, can you help us to understand the mechanism?

Ms Hofferberth. Thank you for your question. Our experience has been that the use of adjunctive bare metal stenting provides a form of supportive scaffolding in the distal aorta, which leads to stabilization of the intimal flap and protection against aneurysmal degeneration. It is our impression that with the bare stent, this mechanism of intimal expansion and stabilization will lead to the development of a static column of blood in the proximal false lumen and thereby assist in aortic remodeling. However, this is only a hypothesis on our part, because it is difficult to specifically evaluate this process directly.
Dr Bridges. However, despite that, you found that the true lumen actually enlarged in the STABLE group.

Ms Hofferberth. Yes, that is correct. After placement of the proximal endograft in the descending thoracic aorta, the dissection-specific bare metal stents are deployed distally by way of the true lumen. Bare metal stenting leads to rapid support and immediate expansion of the true lumen. This reverses true lumen collapse and enhances flow to the distal branch vessels, which helps prevent malperfusion syndromes.

Dr Bridges. So you think that is occurring at deployment, not an indication of a lack of stability subsequently?

Ms Hofferberth. Yes, our results indicate that is the case. We have not presented the data. However, when we considered the size of the true lumen in the thoracic and abdominal aorta immediately after the STABLE procedure, it was the same size that it was at 1 year and at the latest follow-up examinations.

Dr Bridges. Thank you.

Dr Tomislav Mihaljevic (Cleveland, Ohio). The results are very nice, and this is an approach and an evolution. So, from your current experience, what is the contemporary treatment of an emergency-patients with a type A aortic dissection showing up at your institution at 2 o'clock in the morning?

Ms Hofferberth. Thank you for your question. One of the four cardiothoracic surgeons at our institution adopted the STABLE approach for all patients with type A and type B aortic dissection. Patients with type A dissection would receive their proximal open surgical repair, as indicated, and at the time of decannulating the femoral artery, we would then proceed with deploying the proximal graft and the bare metal stent. The adjunctive STABLE repair would usually be conducted at the primary intervention.

Dr Mihaljevic. In all patients with type A dissection?

Ms Hofferberth. The surgeon and interventional radiologist who conducted all these cases implemented this approach with all patients who presented with type A dissection and were admitted under their care.

Dr Mihaljevic. Thank you. 